\title{
Influence of Vertical Mixing on the Thermohaline Hysteresis: Analyses of an OGCM
}

\author{
Matthias Prange, Gerrit lohmann, and André Paul \\ Department of Geosciences, University of Bremen, Bremen, Germany
}

(Manuscript received 14 January 2002, in final form 21 January 2003)

\begin{abstract}
The thermohaline hysteresis response to varying North Atlantic freshwater forcing is studied by means of a three-dimensional global ocean general circulation model (OGCM). The influence of vertical diffusivity is examined using a wide range of mixing coefficients. For sufficiently large vertical diffusivity the model shows a pronounced hysteresis behavior, so that two equilibrium states of the thermohaline circulation are found: one mode with intense deep-water formation in the North Atlantic ("on" mode) and one mode with strongly reduced convective activity ("off" mode). By decreasing the diffusivity, the two branches of the hysteresis merge. In addition, the effect of numerical diffusion is analyzed by applying different advection schemes. A positive feedback between overturning strength and the numerical diffusivity of upstream advection is found, resulting in a reduced stability of the "on" mode. Comparing the results with those from zonally averaged models exhibits substantial differences regarding the stability properties of the thermohaline circulation. Freshwater transports by horizontal gyres have an important effect on the overturning circulation in the OGCM.
\end{abstract}

\section{Introduction}

The present-day circulation of the North Atlantic Ocean transports about $10^{15} \mathrm{~W}$ of heat northward (e.g., Hall and Bryden 1982; Ganachaud and Wunsch 2000). Much of this heat transport is associated with the thermohaline circulation (THC). Previous modeling studies have suggested that the THC can possess multiple equilibria. The present-day circulation is characterized by active North Atlantic Deep Water (NADW) formation ("on" mode). In a so-called "off" mode, convective activity in the North Atlantic is strongly reduced or ceases completely (Manabe and Stouffer 1988; Marotzke and Willebrand 1991). Transitions from one mode to another can be triggered by freshwater perturbations in the North Atlantic (e.g., Bryan 1986; Maier-Reimer and Mikolajewicz 1989; Stocker and Wright 1991; Mikolajewicz and Maier-Reimer 1994). There is paleoclimatic evidence that shifts in the THC occurred in the past, affecting climate in the North Atlantic realm (e.g., Keigwin and Lehman 1994; Clark et al. 2001). In order to understand the past climate history as well as the sensitivity of the climate system to an increase of greenhouse gas concentrations in the atmosphere, it is necessary to identify those factors that control the THC.

One of these factors is determined by vertical (or

Corresponding author address: Dr. Matthias Prange, University of Bremen, Dept. of Geosciences, P.O. Box 330 440, Bremen D-28334, Germany.

E-mail: mprange@palmod.uni-bremen.de diapycnal) mixing in the ocean, providing a mechanism for the conversion of cold deep waters formed in polar and subpolar regions into warm water of the upper layers (e.g., Marotzke 1997; Munk and Wunsch 1998). Utilizing numerical models, previous studies have emphasized the sensitive dependence of overturning strength on vertical mixing (Bryan 1987; Wright and Stocker 1992; Marotzke 1997; Weber 1998; Zhang et al. 1999). Manabe and Stouffer (1999) suggested furthermore that the stability of the THC and the possibility of multiple equilibria depend on vertical diffusion. In particular, they speculated that there is a critical value of diffusivity above which two stable equilibria do not exist.

Unfortunately, values for vertical diffusivity are subject to considerable uncertainty (e.g., Munk and Wunsch 1998). In climate models vertical mixing coefficients are often used to tune the overturning strength in order to obtain realistic oceanic heat transports. Moreover, implicit diffusion can be introduced by numerical advection, with substantial consequences for the meridional overturning (Gerdes et al. 1991). Therefore, sensitivity studies regarding the effect of vertical mixing on THC stability are essential in order to estimate the probability of rapid climate transitions associated with THC modes.

Recently, the thermohaline hysteresis response of Atlantic overturning to varying freshwater forcing and vertical mixing has been analyzed in multibasin zonally averaged ocean models (Ganopolski et al. 2001; Schmittner and Weaver 2001). The authors found that 
large diffusivity reduces the width of the hysteresis loop such that two equilibria only exist in the area of positive freshwater perturbation. Here, we study the hysteresis behavior of the THC in a three-dimensional global ocean general circulation model (OGCM). The influence of vertical diffusivity is examined by using a wide range of mixing coefficients. Furthermore, the effect of numerical diffusion is studied by applying different advection schemes.

\section{Experimental setup}

\section{a. Model and forcing}

The ocean model is based on the Hamburg large-scale geostrophic (LSG) ocean model (Maier-Reimer et al. 1993). The model integrates the momentum equations, including all terms except the nonlinear advection of momentum, by an implicit time integration method that allows a time step of 1 month. The free surface is treated prognostically. The model has 11 vertical levels and a horizontal resolution of $3.5^{\circ}$ on a semistaggered grid type "E" (cf. Mesinger and Arakawa 1976). A new tracer advection scheme for temperature and salinity has been implemented. It is an adaption of the scheme by Farrow and Stevens (1995) using a predictor-corrector method, with a centered difference scheme for the predictor and a third-order QUICK scheme (Leonard 1979) for the corrector stage. Explicit integration of both stages results in a time step constraint that requires the use of subcycles. Here we employ eight subcycles, that is, a time step of 3.75 days for tracer advection. The QUICK scheme is less diffusive than the standard LSG upstream scheme and less dispersive than the common centered difference scheme. Explicit diffusion is necessary to ensure computational stability. Depth-dependent horizontal diffusivities are employed (Bryan and Lewis 1979) ranging from $10^{7} \mathrm{~cm}^{2} \mathrm{~s}^{-1}$ at the surface to $5 \times 10^{6} \mathrm{~cm}^{2} \mathrm{~s}^{-1}$ at the bottom. The use of vertical diffusivities is described below. The LSG ocean model with QUICK advection has been tested thoroughly with various forcings (Schäfer-Neth and Paul 2001).

The ocean model is driven by monthly fields of wind stress, surface air temperature, and freshwater flux provided by the control integration of the atmospheric GCM ECHAM3/T42 (Roeckner et al. 1992). In order to close the hydrological cycle, a runoff scheme transports freshwater from the continents to the ocean. For the surface heat flux $Q$ we use a boundary condition of the form

$$
Q=\left(\lambda_{1}-\lambda_{2} \nabla^{2}\right)\left(T_{a}-T_{s}\right),
$$

as suggested by Willebrand (1993). Here, $T_{a}$ is the prescribed air temperature, and $T_{s}$ denotes the ocean surface temperature. Unlike conventional temperature restoring, the thermal boundary condition (1) allows for scale selective damping of surface temperature anomalies. For the parameters $\lambda_{1}$ and $\lambda_{2}$ we choose $15 \mathrm{~W} \mathrm{~m}^{-2} \mathrm{~K}^{-1}$ and

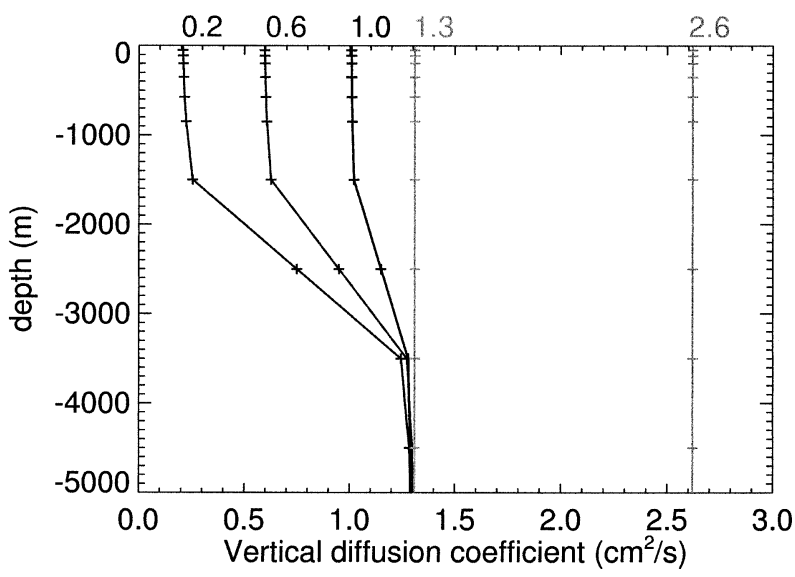

FIG. 1. Profiles of vertical diffusivity used in the present study. Top-level diffusivities are written above the diagram.

$2 \times 10^{12} \mathrm{~W} \mathrm{~K}^{-1}$, respectively. This choice enables the simulation of observed sea surface temperatures as well as the maintenance of large-scale temperature anomalies in the North Atlantic during the hysteresis experiments (see the appendix). Sea surface temperatures are set to the freezing point when grid cells are covered by sea ice or when temperatures fall below the freezing point because of strong surface heat losses.

\section{b. Vertical diffusivity}

In order to examine the influence of vertical diffusivity on the thermohaline hysteresis behavior, we use six versions of the model that differ in vertical mixing. Five versions employ the QUICK advection scheme with explicit horizontal and vertical diffusion. Vertical mixing coefficients are displayed in Fig. 1. The depthdependent diffusivity profiles are based on Bryan and Lewis (1979) except that vertical diffusivities vary between 0.2 and $1.3 \mathrm{~cm}^{2} \mathrm{~s}^{-1}$ in the upper ocean. Accordingly, the different model versions are denoted as V0.2, V0.6, V1.0, and V1.3. Bottom water diffusivity is altered only in version V2.6.

In order to get some insight into the effect of numerical diffusion on THC stability, the sixth version of the model employs the original LSG implicit upstream advection scheme (Maier-Reimer et al. 1993). The upstream scheme is first-order accurate in space and highly diffusive (e.g., Molenkamp 1968). Explicit vertical diffusion is not included in this version.

\section{Results}

a. "On' mode dynamics

Equilibrium Atlantic meridional overturning streamfunctions for the unperturbed (i.e., no freshwater flux anomaly applied) "on'" mode are shown in Fig. 2 for V0.2, V1.0, and V2.6. A strong dependence of overturning strength on vertical diffusivity is detected. The 
(a)

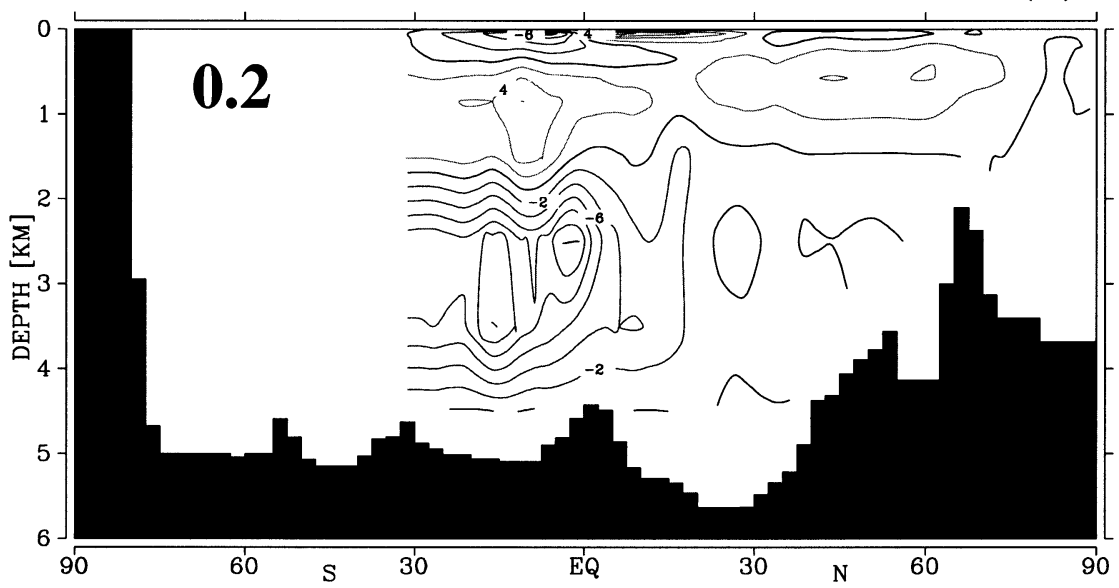

(b)

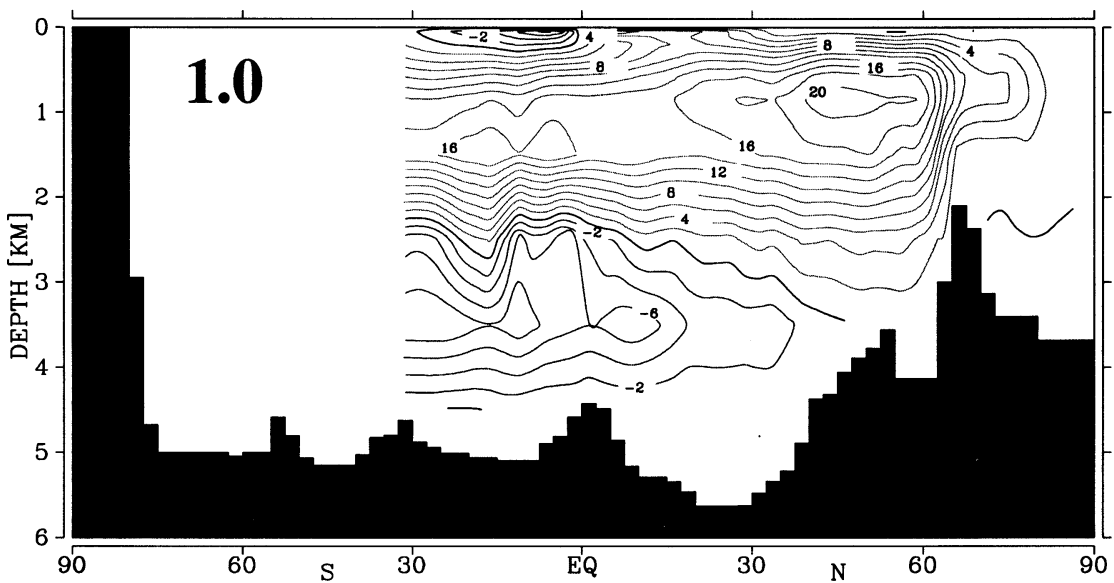

(c)

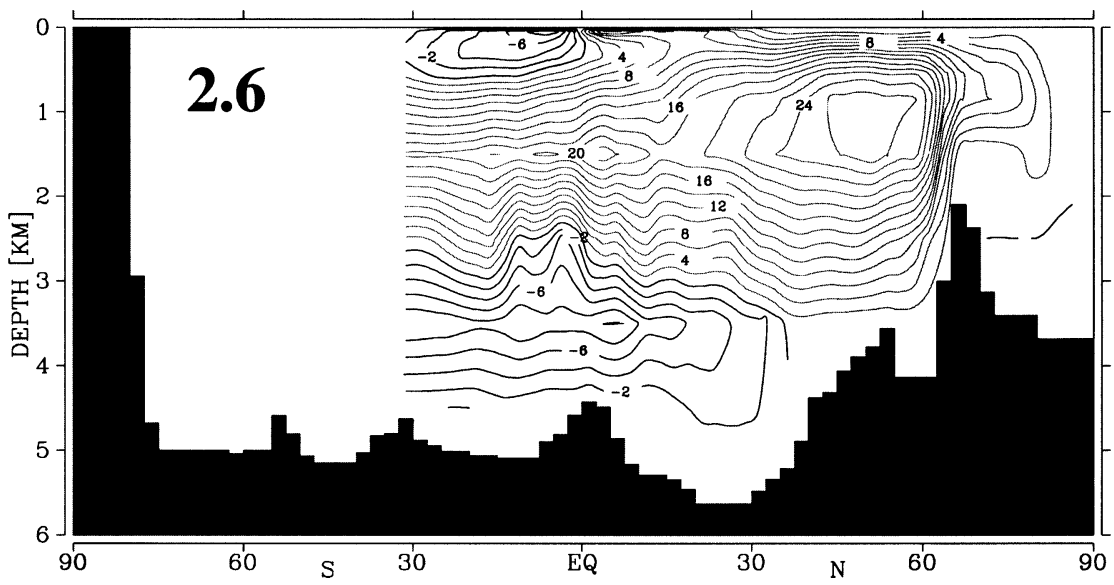

FIG. 2. Atlantic meridional overturning streamfunction $(\mathrm{Sv})$ of the unperturbed (i.e., zero freshwater flux anomaly) "on" mode for (a) V0.2, (b) V1.0, and (c) V2.6. The 40-yr means are shown. 


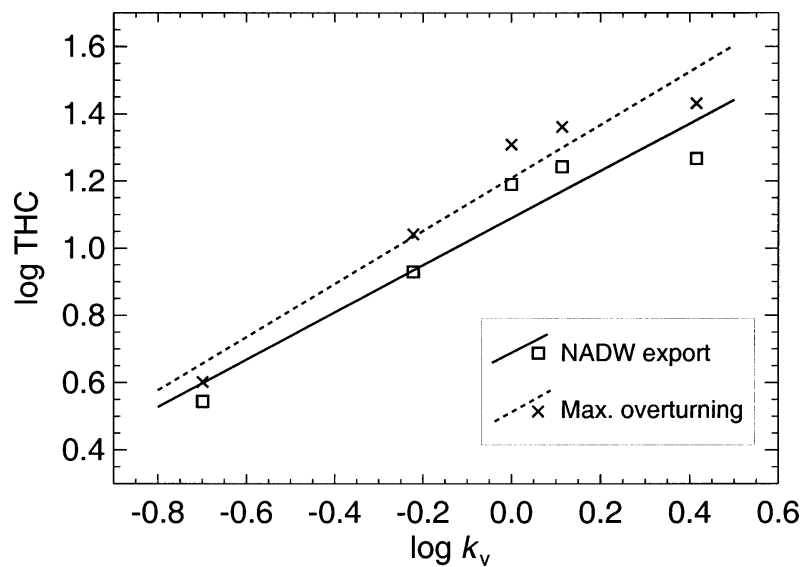

FIG. 3. Maximum North Atlantic overturning (crosses) and NADW export across $30^{\circ} \mathrm{S}$ (squares) against upper-ocean vertical diffusivity in a $\log -\log$ plot for the "on" mode ( $k_{v}$ denotes top-level vertical diffusivity). Values are 40-yr means. Least squares approximations are shown by lines. The gradient of a line corresponds to the exponent of a power law. For North Atlantic maximum overturning (dashed line) the gradient is 0.79 . For NADW export (solid line) the gradient is 0.70 .

low diffusivity in version V0.2 prevents the development of a deep North Atlantic overturning cell. As we shall discuss later, this THC turns out to be monostable. Overturning ratios, that is, ratios of NADW export to the Southern Ocean across $30^{\circ} \mathrm{S}$ and maximum overturning in the North Atlantic, are roughly 0.75 in all model versions employing QUICK advection except for V2.6 where the ratio drops to 0.66 . Southern meridional overturning cells are associated with Antarctic Bottom Water (AABW) formation. The inflow of bottom water to the Atlantic Ocean is about $8 \mathrm{~Sv}\left(\mathrm{~Sv} \equiv 10^{6} \mathrm{~m}^{3} \mathrm{~s}^{-1}\right)$ in all QUICK scheme model versions. This value is consistent with recent inverse modeling results (Ganachaud and Wunsch 2000).

Provided that sinking of NADW is balanced by upwelling in low latitudes, counteracting downward diffusive buoyancy fluxes and maintaining the density stratification (Munk 1966; Munk and Wunsch 1998), simple scaling analysis yields a $2 / 3$ power-law dependence of the meridional overturning $\Phi$ on vertical diffusivity $k_{v}$ and a $1 / 3$ power-law dependence of $\Phi$ on the upper-ocean density range $\Delta \rho$ (e.g., Winton 1996; Marotzke 1997; Klinger and Marotzke 1999; Zhang et al. 1999); that is,

$$
\begin{aligned}
\Phi & \sim k_{v}^{2 / 3} \Delta \rho^{1 / 3} \quad \text { or } \\
\log \Phi-\frac{1}{3} \log \Delta \rho & \sim a \log k_{v}, \quad a=\frac{2}{3} .
\end{aligned}
$$

To test the validity of these scalings in our model, we plot overturning strength against upper-ocean vertical diffusivity, ignoring changes in the meridional density gradient (Fig. 3). We find exponents $a_{\mathrm{OGCM}}=0.70$ and 0.79 for NADW export at $30^{\circ} \mathrm{S}$ and North Atlantic maximum overturning, respectively. As the meridional den-

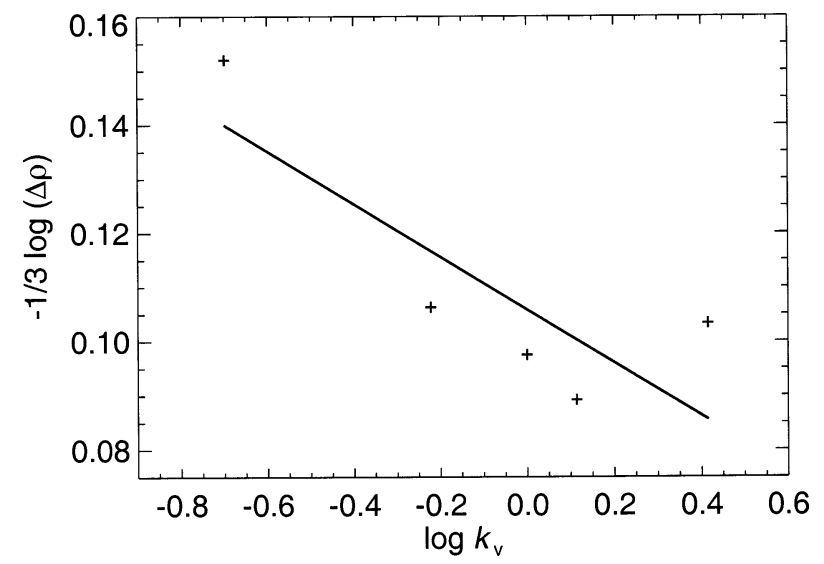

FIG. 4. Relation between meridional density gradient in the Atlantic Ocean and upper-ocean vertical diffusivity for the "on" mode $\left(k_{v}\right.$ denotes top-level vertical diffusivity). As a measure for the density gradient we define $\Delta \rho=\bar{\sigma}_{N}-\bar{\sigma}_{S}$, where $\bar{\sigma}_{N}$ and $\bar{\sigma}_{S}$ denote zonally and vertically averaged potential densities in the North Atlantic (at $65^{\circ} \mathrm{N}$ ) and in the South Atlantic (at $30^{\circ} \mathrm{S}$ ). Vertical averaging is over the entire depth of the NADW overturning cell at $65^{\circ} \mathrm{N}$ and over the depth of the upper limb of the overturning circulation at $30^{\circ} \mathrm{S}$ (this depth varies from $1000 \mathrm{~m}$ in V0.2 to $1500 \mathrm{~m}$ in V2.6). The gradient of the least squares approximation in the $\log -\log$ plot is -0.05 . According to (3), this gradient has to be taken into account when testing the validity of the $2 / 3$ power law (2) in our OGCM.

sity gradient actually increases with vertical mixing (chiefly as a result of increasing densities in the northern Atlantic), these exponents have to be corrected to take into account the $1 / 3$ power dependence on $\Delta \rho$. According to Fig. 4 , this correction amounts to -0.05 . Adding this value to $a_{\mathrm{OGCM}}$ yields the actual power law dependence of overturning on vertical diffusivity in the OGCM, which is indeed close to $a=2 / 3$. We emphasize that in our experiments vertical mixing below $3000 \mathrm{~m}$ is significantly altered only in version V2.6 (Fig. 1). Therefore, our result confirms previous model studies (e.g., Cummins et al. 1990; Scott and Marotzke 2002), demonstrating that the effect of vertical mixing on overturning is most important where vertical density gradients are largest, that is, in the low-latitude upper ocean at thermocline depths. Deep and bottom water mixing does not contribute significantly to the strength of the NADW overturning circulation (Scott and Marotzke 2002).

Toggweiler and Samuels (1995) found a strong sensitivity of NADW overturning to changes in Southern Ocean wind stress. An additional experiment with version V0.6 shows that this "Drake Passage effect" is weak in our model. A $50 \%$ increase of wind stresses over the Southern Ocean yields an amplification of the meridional overturning by only $7 \%$.

Figure 5 shows the unperturbed "on" mode Atlantic meridional overturning for the upstream version of the ocean model. The maximum overturning in the North Atlantic is close to that of V2.6, reflecting the high numerical diffusion of the upstream advection scheme. Nevertheless, the meridional overturning circulation dif- 


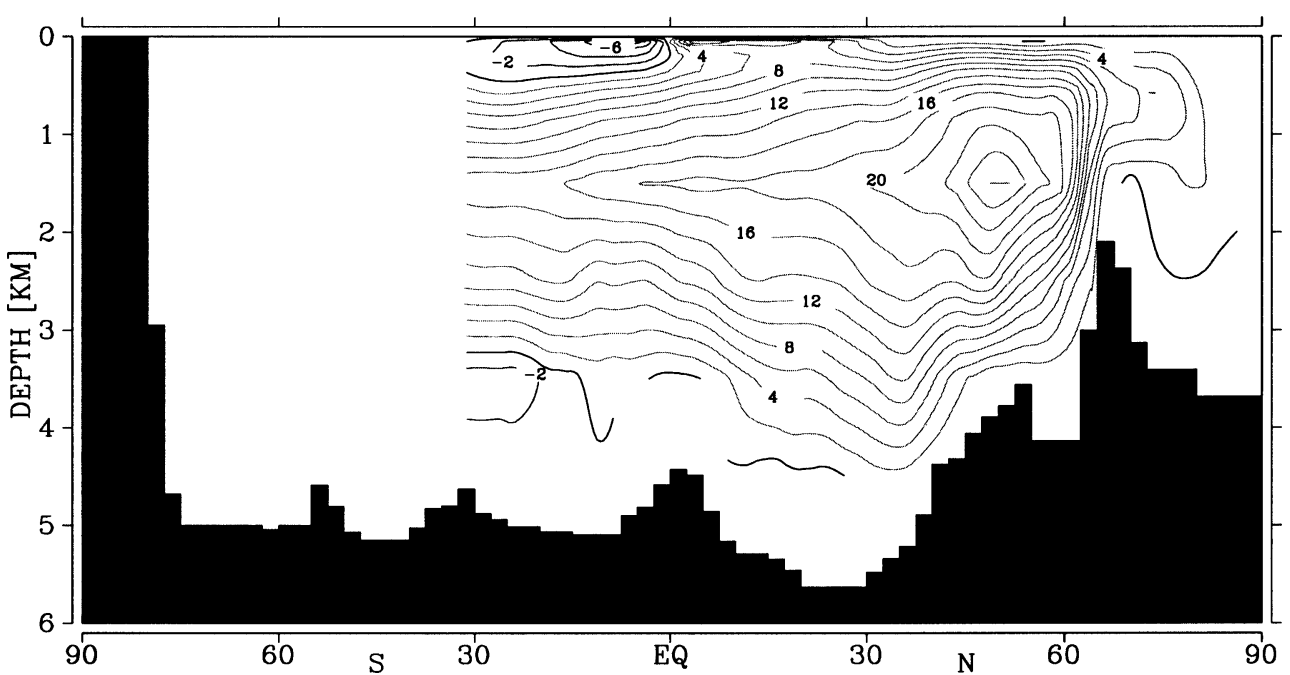

FIG. 5. Atlantic meridional overturning streamfunction $(\mathrm{Sv})$ of the unperturbed "on" mode using upstream advection. A 40-yr mean is shown.

fers substantially from the QUICK scheme results. The export of NADW at $30^{\circ} \mathrm{S}$ is much smaller, resulting in an overturning ratio of only 0.55 , and the southern overturning cell is extremely weak. We emphasize that the numerical diffusivity of the upstream advection scheme is proportional to the flow velocity, and hence varies in time and space (e.g., Molenkamp 1968). This gives rise to a positive feedback between overturning strength and vertical diffusivity: numerical diffusivity increases as the overturning strengthens, leading to a further amplification of the overturning. Moreover, large numerical diffusion also arises in horizontal direction affecting the

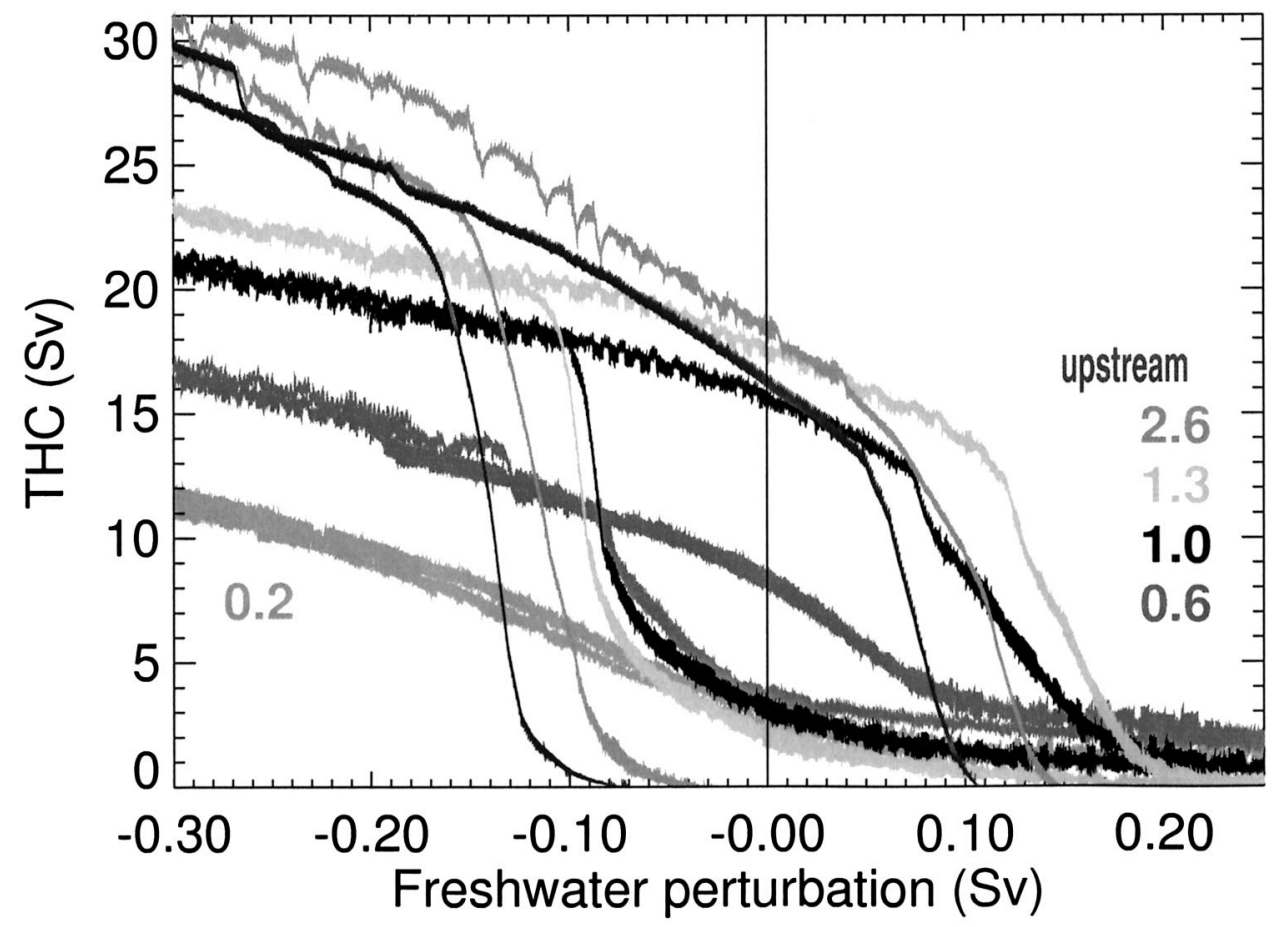

FIG. 6. Meridional overturning at $30^{\circ} \mathrm{S}$ against surface freshwater flux anomaly in the North Atlantic for model versions with different vertical mixing: QUICK scheme versions V0.2, V0.6, V1.0, V1.3, V2.6, and version with upstream advection. The hysteresis loops are obtained as follows: Integration starts at the upper branch with zero freshwater perturbation. The freshwater input is then slowly increased until $0.35 \mathrm{~Sv}$. The integration proceeds on the lower branch with freshwater input decreasing until $-0.35 \mathrm{~Sv}$. Then the freshwater input increases again to close the loop. 
(a)

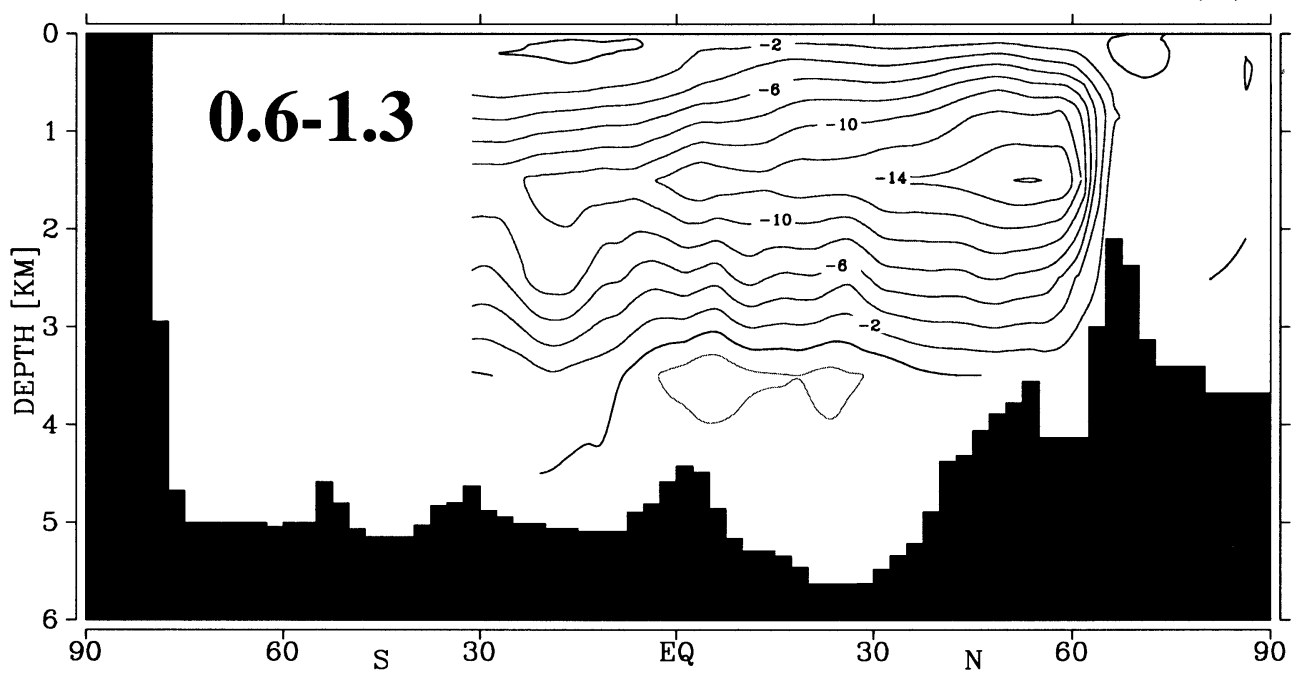

(b)

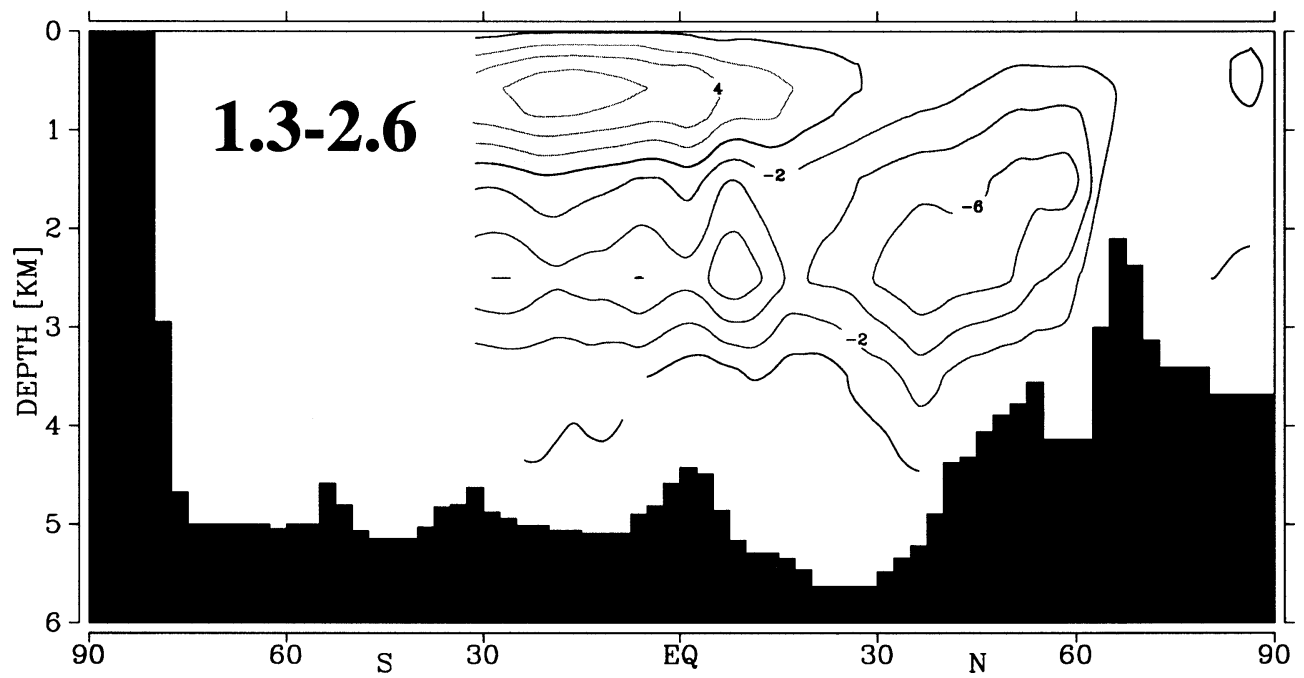

FIG. 7. Difference of the unperturbed "on" mode Atlantic meridional overturning between (a) V0.6 and V1.3 and between (b) V1.3 and V2.6 (Sv). The 40-yr means are shown.

circulation. Therefore, it is not possible to mimic the upstream numerical diffusivity by using a higher order advection scheme together with large (vertical) explicit diffusion as suggested by Manabe and Stouffer (1999).

\section{b. Hysteresis curves}

For each version of the model, the hysteresis behavior of the THC is studied by applying a slowly varying surface freshwater flux perturbation to the North Atlantic. Starting from the equilibrium "on" mode, the freshwater flux is changed by $0.05 \mathrm{~Sv}$ per 1000 years. Following Ganopolski and Rahmstorf (2001) the freshwater perturbation is uniformly added in the latitude belt $20^{\circ}-$ $50^{\circ} \mathrm{N}$ to be in the Northern Hemisphere, but to avoid forcing convection regions directly. The freshwater flux is not compensated elsewhere. Because of the slowly varying nature of the surface forcing the model is in quasi equilibrium during the integration except during mode transitions (cf. Rahmstorf 1995). Resulting hysteresis loops are shown in Fig. 6, where the export of NADW across $30^{\circ} \mathrm{S}$ is plotted against the applied surface freshwater flux anomaly.

Apart from V0.2, a pronounced hysteresis behavior is evident in all model versions. Starting from zero perturbation, an increased freshwater input to the North Atlantic reduces North Atlantic salinity, and hence density, weakening thermohaline overturning. When the 


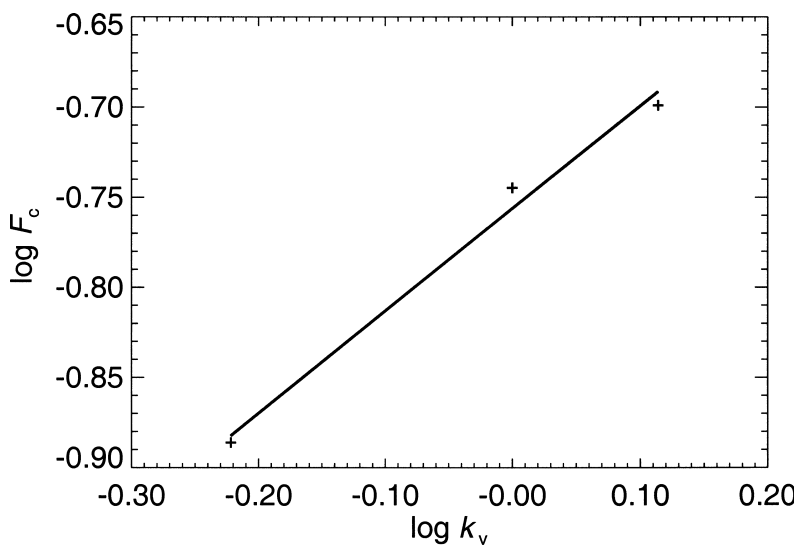

FIG. 8. Critical freshwater perturbation $F_{c}$, required to shut down the "on" mode (see the text for an exact definition), against upperocean vertical diffusivity in a $\log -\log$ plot $\left(k_{v}\right.$ denotes top-level vertical diffusivity). The gradient of the least squares approximation is 0.57 . It corresponds to the exponent of a power law.

freshwater perturbation gets strong enough, the "off", mode becomes the only equilibrium solution for the oceanic circulation. Once the THC is in the "off" mode, a negative freshwater flux anomaly (i.e., net evaporation) is required to switch back to the "on" mode. In order to understand the influence of vertical mixing on the oceanic hysteresis behavior, it is necessary to analyze the stability properties of both "on" and "off", modes.

\section{c. Vertical mixing and stability of the "on" mode}

For vertical diffusion coefficients up to $1.3 \mathrm{~cm}^{2} \mathrm{~s}^{-1}$, the anomalous freshwater flux necessary to stop NADW formation increases with diffusivity. To understand this, the Atlantic overturning difference between V0.6 and V1.3 is shown in Fig. 7a. The stronger overturning in the more diffusive version of the model is associated with an increased supply of high-saline, warm nearsurface waters to the northern Atlantic, and an intensified return flow of relatively fresh and cold deep water masses. The overturning circulation thus acts to reduce the meridional gradients of temperature and salinity imposed by the surface fluxes. Since the evolution of the temperature field is restricted by variable surface heat fluxes, the meridional overturning acts more effectively on salinity and, hence, tends to increase the density of North Atlantic water masses. Therefore, a stronger THC is less sensitive to freshwater perturbations due to higher North Atlantic densities and an effective meridional mixing of salinity anomalies by the large-scale overturning circulation.

A theoretical study by Zhang et al. (1999) suggests that the critical freshwater perturbation $F_{c}$, required to shut down the thermally driven THC, scales with a $2 / 3$ power with vertical diffusivity; that is, $F_{c} \sim k_{v}^{2 / 3}$. Defining $F_{c}$ as the freshwater input at which the upper branch of a hysteresis joins its lower branch in the area of positive freshwater perturbation (see Fig. 6), we plot $F_{c}$ against upper-ocean vertical diffusivity for the bistable versions of our model with diffusion coefficients up to $1.3 \mathrm{~cm}^{2} \mathrm{~s}^{-1}$ (Fig. 8). We find a slightly weaker power law dependence of $F_{c}$ on mixing than suggested by the scaling analysis, with an exponent of 0.57 . This discrepancy can partly be attributed to the simplifying assumptions of fixed temperatures and zero freshwater transports by horizontal gyres in the derivation of the 2/3 power law.

The monotonic relation between vertical diffusivity and critical freshwater perturbation breaks down for very large diffusion coefficients. In order to elucidate the ocean's response to very large thermocline diffusivity, we look at the Atlantic overturning difference between V1.3 and V2.6 (Fig. 7b). An upper southern overturning cell emerges from the difference plot, which is associated with strong upwelling through the tropical thermocline. This strong upwelling is an essential element of the overturning circulation in the highly diffusive version of the model, maintaining stratification by a vertical advective-diffusive density balance. As a result, the near-surface transport of high-saline water from the southern subtropics to the North Atlantic is substantially reduced in V2.6. The northward transport of fresher water masses leads to lower salinities, and hence densities, in the North Atlantic, making the THC more sensitive to freshwater perturbations in the highly diffusive case.

As to the THC's stability in the upstream version, the positive feedback between overturning strength and numerical diffusivity must be taken into account. As the THC becomes weaker with increasing freshwater perturbation, numerical diffusion decreases, causing a further reduction in overturning strength. This destabilizing feedback results in a strong decline of the hysteresis curve's upper branch when upstream advection is used (Fig. 6).

The unperturbed meridional overturning streamfunction of V0.2 shows only a weak circulation in the North Atlantic (Fig. 2a). Water masses formed by convection do not sink below intermediate depths. Applying a positive freshwater flux anomaly to the North Atlantic hardly affects this overturning pattern. A negative anomaly, on the other hand, favors NADW formation such that the overturning strengthens (Fig. 6). By no means we are able to generate multiple equilibria. The hysteresis behavior vanishes with the small diffusivity of V0.2 in our model, and the THC turns out to be monostable.

\section{d. "Off" mode dynamics}

Equilibrium Atlantic meridional overturning streamfunctions for the unperturbed "off" mode are shown in Figs. 9a,b for V0.6 and V1.3 and in Fig. 10 for the upstream version. In contrast to the "on" mode of the THC, huge southern cells dominate the meridional cir- 
(a)

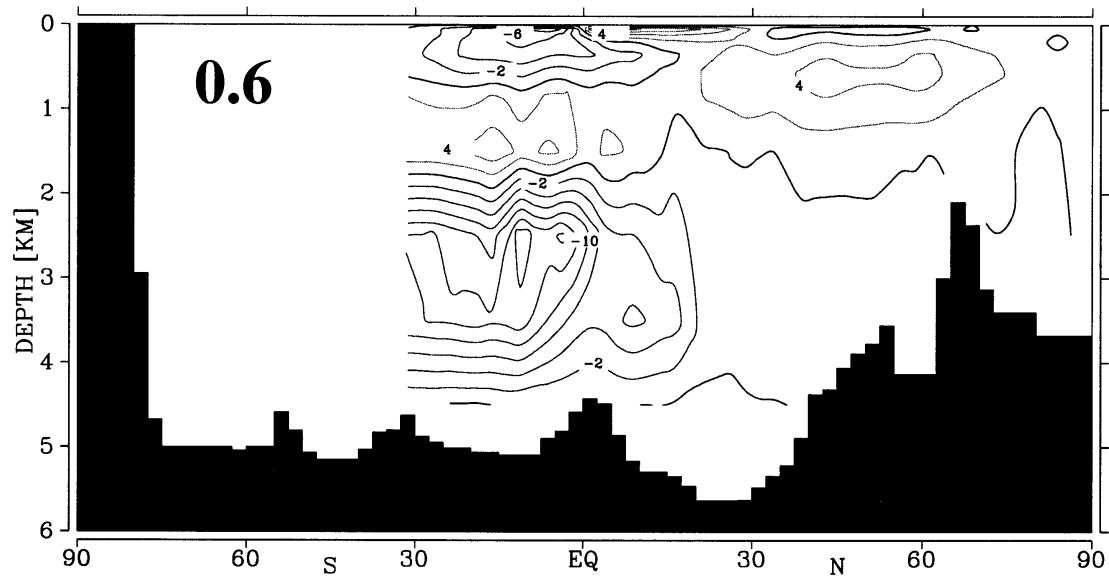

(b)

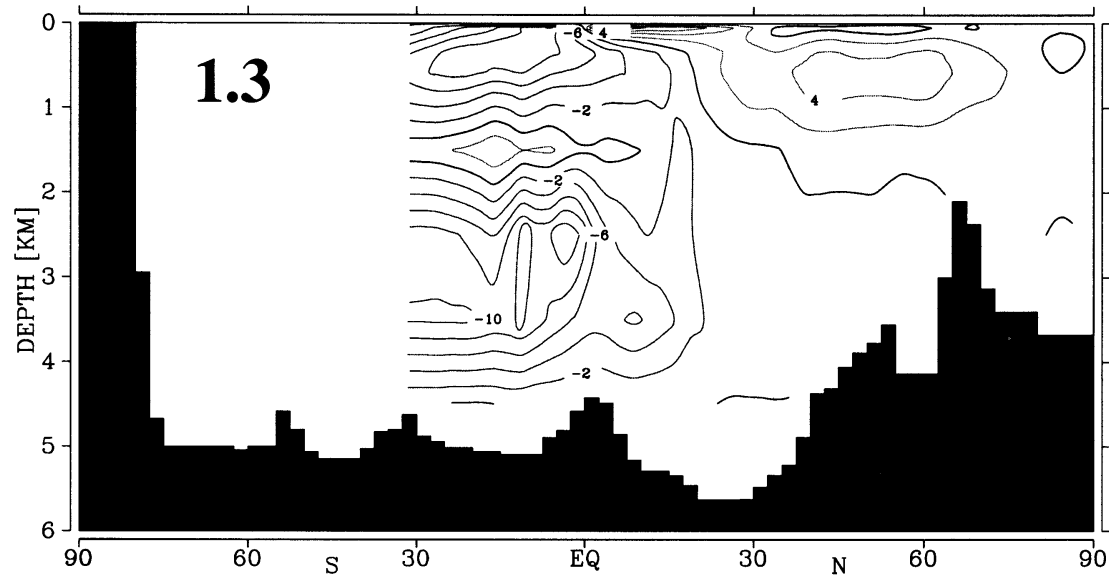

(c)

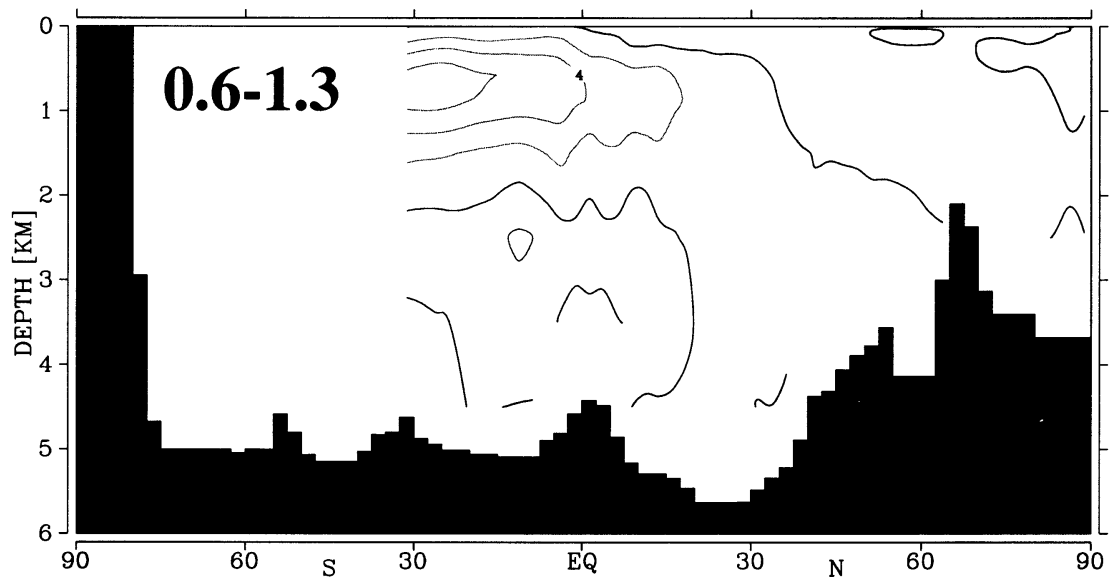

FIG. 9. Atlantic meridional overturning streamfunction (Sv) of the unperturbed "off" mode for (a) V0.6 and (b) V1.3. (c) Difference plot is shown. The 40-yr means are shown. 


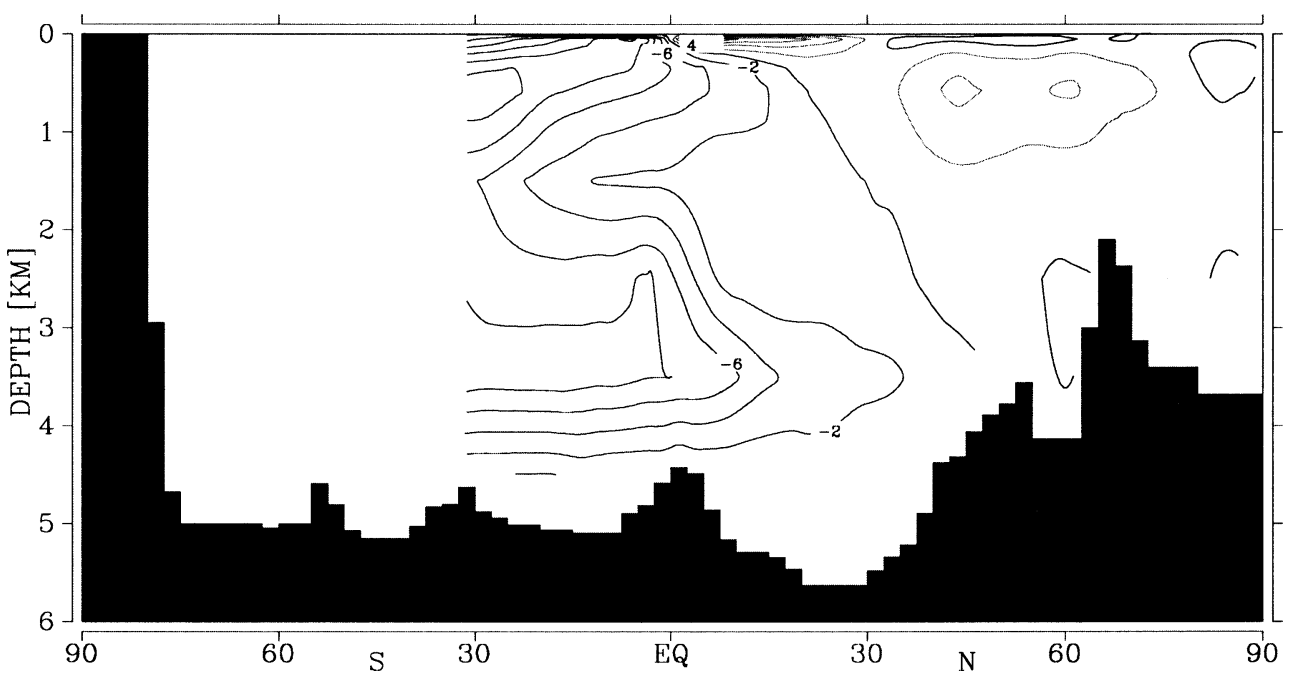

FIG. 10. Atlantic meridional overturning streamfunction (Sv) of the unperturbed "off" mode using upstream advection. A 40-yr mean is shown.

culation, filling the abyssal Atlantic Ocean with Antarctic water masses.

Although northern convective activity is considerably reduced compared to the "on" mode, there is still some open-ocean convection in the Nordic seas (Fig. 11). The presence of a cyclonic, wind-driven gyre is associated with a doming of isopycnals in the center of the Nordic seas, causing a local surface salinity maximum at about $70^{\circ} \mathrm{N}$ (Figs. 12a,b). This favors the maintenance of convective activity, and water masses formed by winter convection are denser than their surroundings. Hence, a weak and shallow overturning cell appears in the North Atlantic in all versions of the model. In the low-diffusion versions, this overturning cell is connected with the South Atlantic (Fig. 9a). With enhanced vertical mixing coefficients, the southern upper (Ekman-dominated) overturning cell deepens, thereby separating the North Atlantic overturning cell from the South Atlantic (Fig. 9b). Deepening of the southern cell is associated with intensified net upwelling in low latitudes (Fig. 9c), balancing increased downward mixing of buoyancy.

In the "off" mode of the THC, AABW represents the saltiest water mass in the deep Atlantic (Fig. 12a). Its abyssal flow is associated with a northward salt transport, while the upper-ocean salt transport from the South to the North Atlantic is substantially reduced. As a result, the upper North Atlantic and the Nordic seas are very fresh (Fig. 12b), and water masses there are relatively light.

\section{e. Vertical mixing and stability of the "off" mode}

From the hysteresis loops in Fig. 6 we can see that a negative freshwater flux anomaly is required to switch from the "off" mode to the "on" mode. In the following, we examine why such a transition requires a stronger net evaporation with increasing vertical mixing.
The difference plot (V0.6 - V1.3) in Fig. 9c reveals a strong influence of vertical diffusivity on upper-ocean overturning in the South and tropical Atlantic, whereas the circulation is almost unchanged in the deep ocean and in the North Atlantic. The reduced flow of highsalinity upper-ocean water from the South to the North Atlantic in version V1.3 results in a lower North Atlantic mean salinity in comparison with V0.6 (Figs. 12c,d). Enhanced vertical mixing thus leads to increased northward freshwater transports by the meridional overturning circulation.

For a quantitative analysis we define the overturning component of the northward freshwater transport in the Atlantic Ocean as

$$
F_{\text {ot }}=\int_{-h}^{0}\left(\frac{S_{r}-\bar{S}}{S_{r}}\right) \bar{v} d z,
$$

where $h$ is the ocean depth, $S_{r}$ is a reference salinity (mean salinity of the Atlantic Ocean), and $\bar{S}$ and $\bar{v}$ denote zonally averaged salinity and integrated northward velocity, respectively. In equilibrium, the total meridional freshwater transport $F$ is uniquely determined by the constant surface freshwater forcing. Neglecting horizontal diffusion, $F$ can be separated into the overturning component $F_{\text {ot }}$ and the meridional freshwater transport by the horizontal gyre circulation $F_{\text {hor }}$; that is,

$$
F=F_{\text {ot }}+F_{\text {hor }}=\text { const. }
$$

In contrast to zonally averaged models of the ocean, where $F_{\text {hor }}=0, F_{\text {ot }}$ can vary in a three-dimensional model. The overturning transport of freshwater from the South Atlantic into the North Atlantic, that is, $F_{\text {ot }}$ at the equator, is displayed in Fig. 13 for the "off" mode of the different model versions. The cross-equatorial freshwater flow $F_{\text {ot }}$ increases with vertical mixing, thereby making the North Atlantic fresher and the South Atlantic 


\section{on mode}

(a)

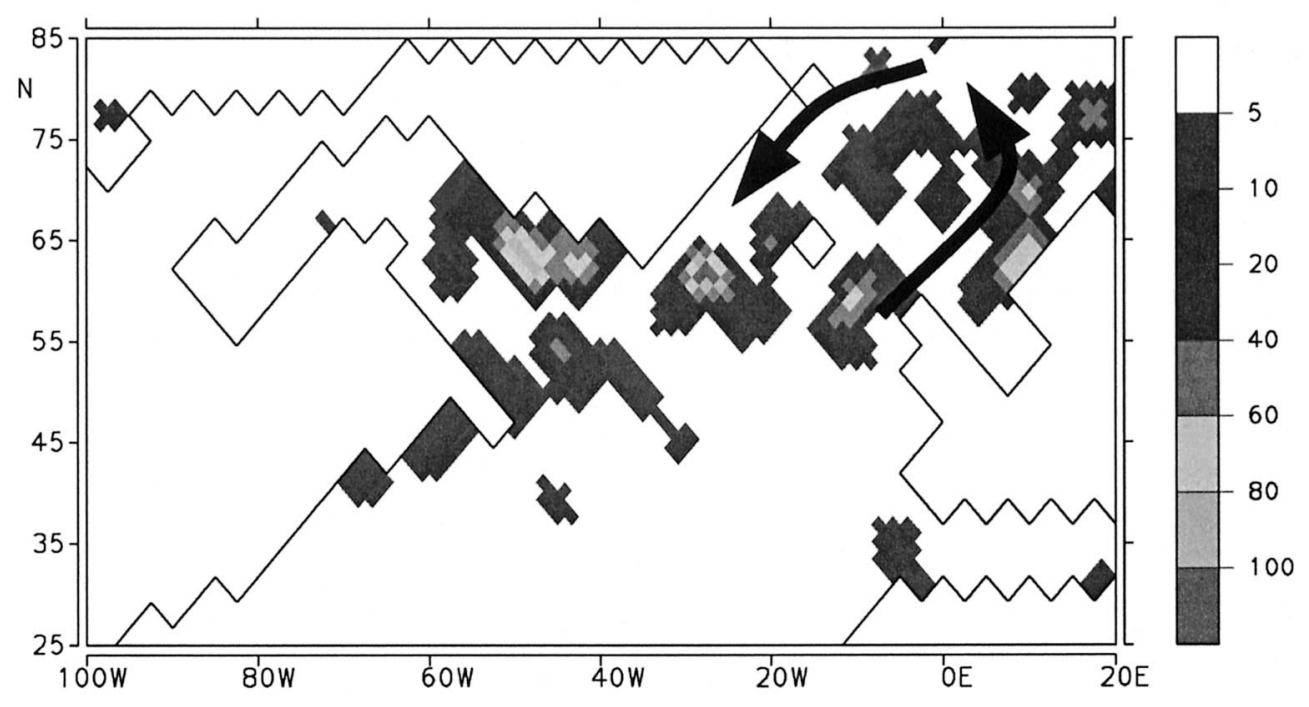

off mode

(b)

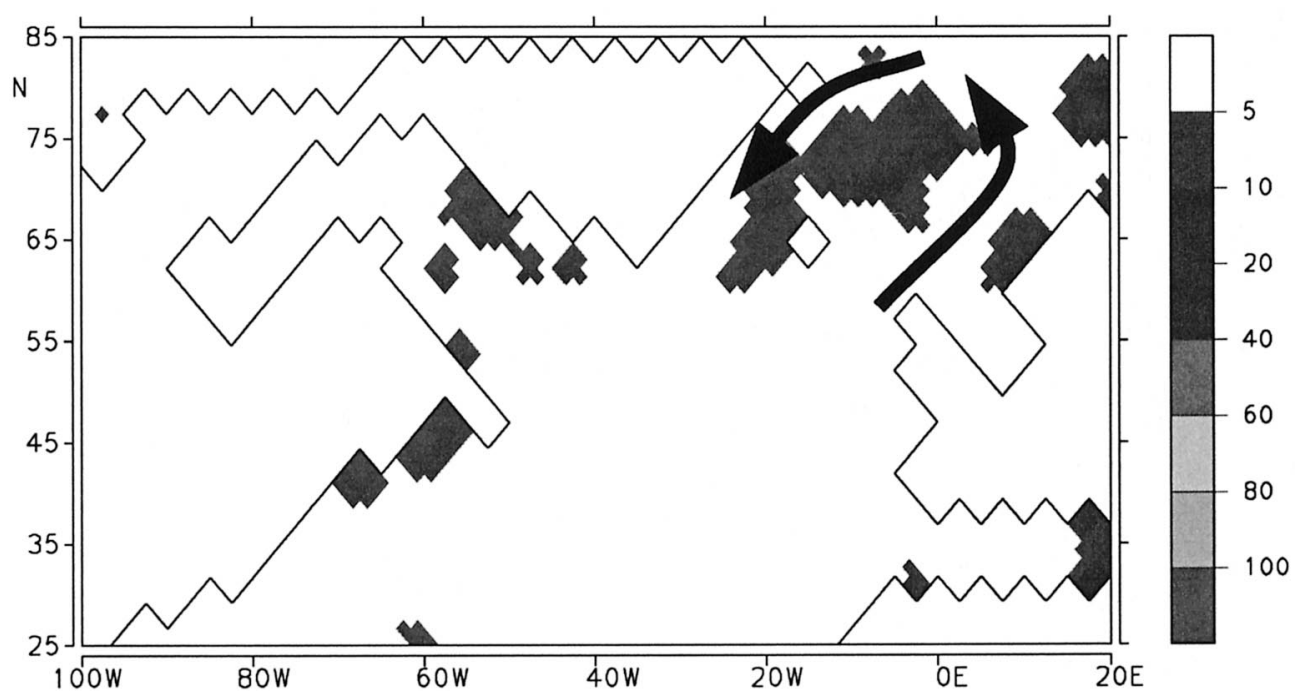

FIG. 11. Potential energy dissipation due to convection in the North Atlantic and the Nordic seas using model version V1.3 for unperturbed (a) "on" and (b) "off" modes. The 40-yr means are shown; units are 10-3 W $\mathrm{m}^{-2}$. The cyclonic circulation in the Nordic seas is drawn schematically.

saltier (cf. Fig. 12c). This can be understood by using the scaling

$$
F_{\text {hor }} \sim-\Psi \Delta S
$$

as a lowest order approximation, where $\Delta S$ is the difference between North and South Atlantic salinities, and $\Psi$ denotes the volume flux of the horizontal gyre circulation. Here $\Psi$ is primarily a function of wind stress and, thus, nearly constant in our experiments. Inserting
(6) into (5) shows that $\Delta S$ is proportional to the overturning freshwater transport $F_{\mathrm{ot}}$ :

$$
\Delta S \sim \Psi^{-1}\left(F_{\text {ot }}-F\right) .
$$

Regarding deep overturning, the density of North Atlantic water competes with water masses from the Southern Ocean. Low densities in a relatively fresh North Atlantic implicate high stability of the "off" mode. Since the salinity difference $\Delta S$ increases with 


\section{6}

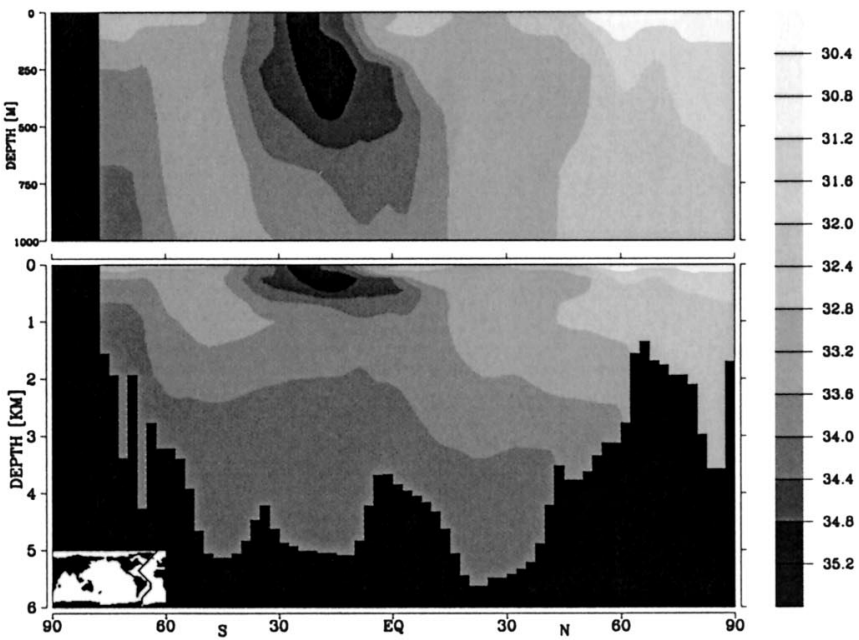

0.6-1.3

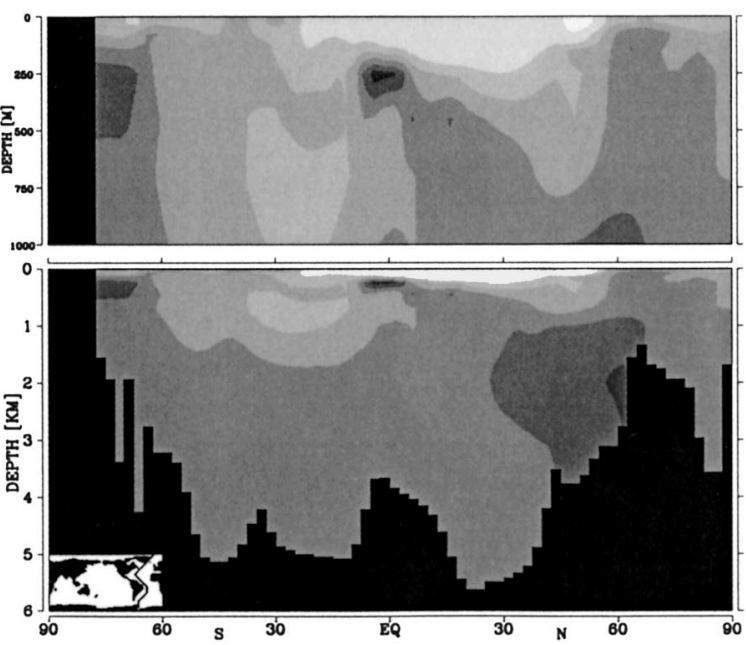

0.6

(b)

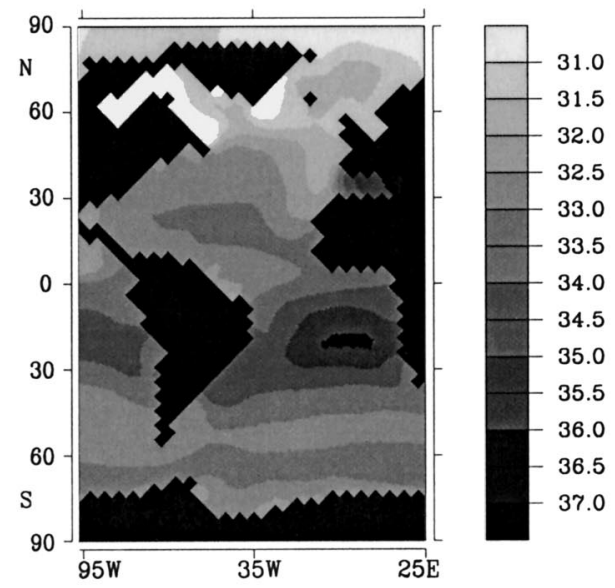

0.6-1.3

(d)

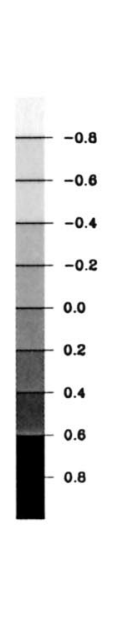

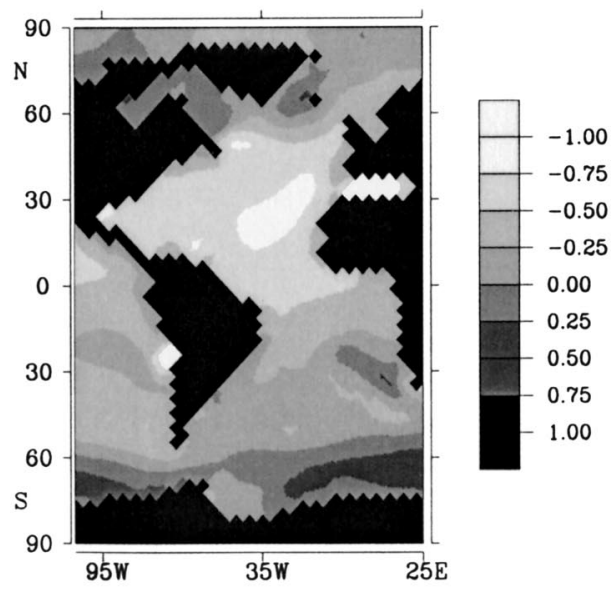

Fig. 12. "Off" mode salinity distribution in the Atlantic Ocean along (a) a western section and (b) on a horizontal cut at 75-m depth, i.e., on the second level of the model grid, for version V0.6. (c), (d) Differences relative to V1.3; 40-yr means are shown.

enhanced vertical diffusivity (Fig. 13), larger evaporation anomalies are required to destabilize the "off" mode.

\section{Comparison with two-dimensional models}

Recently, the hysteresis response of Atlantic overturning to varying freshwater forcing and vertical diffusivity has been analyzed using zonally averaged ocean models (Schmittner and Weaver 2001; Ganopolski et al. 2001). To what extent are the results from these twodimensional models comparable with our findings?

\section{a. "On'” mode}

With increased vertical mixing the Atlantic overturning of the "on" mode becomes stronger in the twodimensional ocean model of Schmittner and Weaver (2001). However, the dependence of overturning strength on the diffusion coefficient is weak in their model. Assuming a power-law dependence, the exponent is only 0.18 (Schmittner and Stocker 2001), and even for diffusivities as low as $10^{-2} \mathrm{~cm}^{2} \mathrm{~s}^{-1}$ the overturning circulation is strong, with a North Atlantic maximum of about $20 \mathrm{~Sv}$ in the absence of surface fresh- 


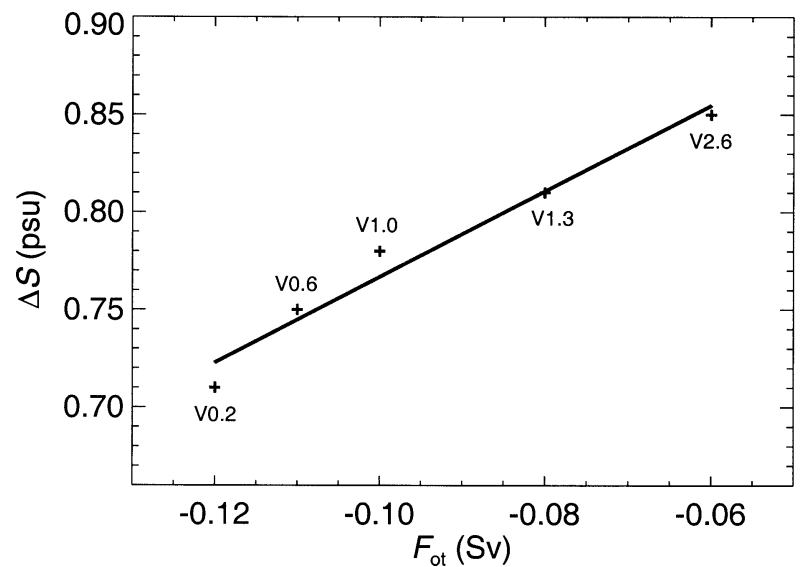

FIG. 13. Salinity contrast between North and South Atlantic against northward freshwater transport by the overturning circulation $F_{\mathrm{ot}}$ across the equator for the unperturbed "off" mode of the different QUICK scheme model versions. We define $\Delta S=\bar{S}_{S}-\bar{S}_{N}$, where $\bar{S}_{S}$ is the salinity averaged over the entire South Atlantic, and $\bar{S}_{N}$ denotes the salinity averaged over the North Atlantic and Arctic Oceans. Values are 40-yr means. $F_{\text {ot }}$ is defined as in (4), calculated on a monthly base, and averaged over 40 years. The solution of the least squares approximation is plotted in the diagram. According to (7), the gradient scales with the inverse of the volume flux by the horizontal gyre circulation. The total northward freshwater transport across the equator amounts to $-0.19 \mathrm{~Sv}$.

water flux perturbations. It is likely that the upstream advection scheme used in the zonally averaged model (A. Schmittner 2001, personal communication) is responsible for this behavior. Numerical diffusion can be of the same order as explicit diffusion when upstream advection without any additional antidiffusive fluxes is applied in ocean models (Gerdes et al. 1991). Numerical diffusion probably dominates in the low-diffusivity experiments of Schmittner and Weaver (2001), thus reducing the sensitivity of overturning strength to changes in the vertical diffusion coefficient.

\section{b. "Off" mode}

Regarding the stability of the "off" mode, fundamental differences between zonally averaged models and our OGCM are exhibited. Vertical mixing tends to stabilize the "off" mode in our OGCM, thereby widening the hysteresis loop. By contrast, large diffusivity reduces the width of the hysteresis in the two-dimensional models of Schmittner and Weaver (2001) and Ganopolski et al. (2001). Schmittner and Weaver (2001) explained their model's behavior by the weakened density stratification in the North Atlantic when strong vertical mixing is applied: a smaller increase in surface salinity is sufficient to destabilize the stratification, activate convection, and induce a mode transition. In our OGCM, where convective activity is weak, but still active in the Nordic seas, another mechanism controls the influence of vertical mixing on the stability of the "off" mode. Increased vertical diffusivity results in a deep- ening of the southern upper overturning cell. Changes of this overturning cell alter freshwater transports, North Atlantic salinities, and hence the stability of the "off" mode.

Different "off" mode dynamics in two-dimensional models can be attributed to the absence of freshwater transports by horizontal gyres. Because of excess precipitation and river runoff there is a freshwater surplus in the North Atlantic/Nordic seas. In equilibrium, this surplus is balanced by the ocean circulation, exporting freshwater southward. In the "off" mode circulation found in our OGCM, a weak and shallow overturning cell is present in the North Atlantic. It is associated with convective activity in the Nordic seas, which is favored by a cyclonic wind stress in that region. This overturning cell is not very efficient with respect to freshwater transport. Instead, a major portion of freshwater is exported from the northern North Atlantic by the anticyclonic gyre circulation, as can be seen from Fig. $12 \mathrm{~b}$ by the tongue of low-salinity water in the eastern North Atlantic. In two-dimensional models, all freshwater has to be transported by the overturning circulation alone. This constraint leads to a different "off" mode overturning pattern that is characterized by a single reversed circulation cell with deep upwelling reaching far into the northern North Atlantic (Stocker and Wright 1991; Stocker et al. 1992; Ganopolski et al. 2001).

\section{Concluding remarks}

We studied the influence of vertical mixing on the THC and its hysteresis behavior using a three-dimensional OGCM. We found that the stability properties of the THC are closely linked to freshwater transports by the overturning circulation that, in turn, strongly depend on upper-ocean vertical diffusivity. For sufficiently large vertical mixing, we found a pronounced hysteresis behavior in our model. By decreasing the diffusivity, the two branches of the hysteresis merge, and the THC becomes monostable for very small vertical diffusivity. The speculations of Manabe and Stouffer (1999) cannot be confirmed by our OGCM since a critical diffusivity, above which two stable equilibria do not exist, was not found.

By comparing our results with those from two-dimensional models (Schmittner and Weaver 2001; Ganopolski et al. 2001), discrepancies regarding the stability of the "off" mode were exhibited. The results suggest that processes, important for "off" mode dynamics, are different in two-dimensional and three-dimensional models. In particular, freshwater transports by horizontal gyres have a significant effect on the overturning circulation in our OGCM. More general, we conclude that all model properties that affect horizontal gyre transports of freshwater (e.g., horizontal resolution, bottom topography) have a potential influence on THC dynamics and stability.

Furthermore, we studied the influence of numerical 
diffusion by applying different advection schemes (QUICK, upstream). The results suggest that numerical diffusion can change the stability properties of the THC substantially. We point to a positive feedback between overturning strength and numerical diffusivity, making the conveyor more vulnerable. This unphysical effect has implications for climate scenario integrations and possibly results in overestimated changes of the THC in models that employ upstream advection without adding antidiffusive fluxes.

Acknowledgments. We are grateful to K. Herterich for his support. We appreciate the stimulating discussions with R. Keeling and M. Butzin. Very helpful suggestions by two anonymous referees have been utilized to improve the paper considerably. We kindly acknowledge financial support from the German Federal Ministry for Education, Science and Research (BMBF).

\section{APPENDIX}

\section{Influence of the Surface Heat Flux Parameters $\lambda_{1}$ and $\lambda_{2}$ on Sea Surface Temperatures and THC Stability}

The surface heat flux formulation (1) allows for scale selective damping of sea surface temperature anomalies, and is therefore superior to the conventional restoring approach. Applying $\lambda_{1}=15 \mathrm{~W} \mathrm{~m}^{-2} \mathrm{~K}^{-1}$ and $\lambda_{2}=2$ $\times 10^{12} \mathrm{~W} \mathrm{~K}^{-1}$ in our model setup, the timescale for surface restoring can vary from one month for smallscale temperature anomalies to almost one-half year for

(a)

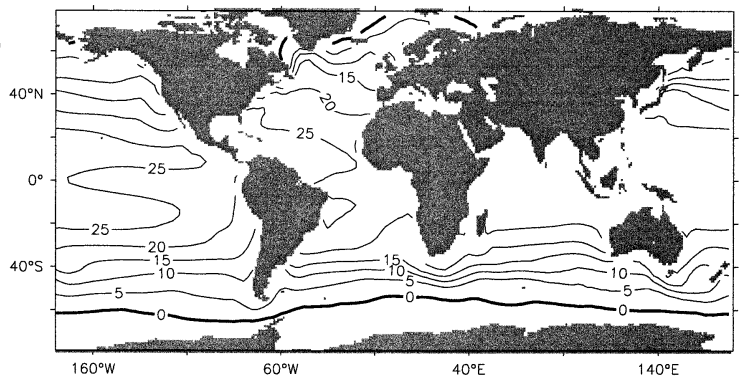

(b)

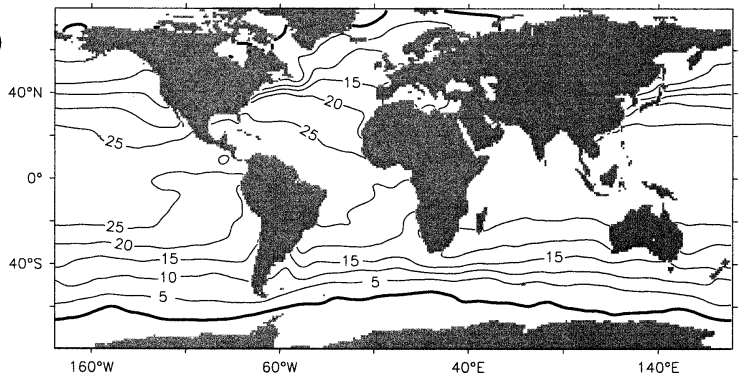

FIG. A1. Sea surface temperatures $\left({ }^{\circ} \mathrm{C}\right)$ simulated by the OGCM (version V0.6: "on" mode without surface freshwater flux perturbation; 40-yr mean) using (a) the heat flux parameters $\lambda_{1}=15 \mathrm{~W}$ $\mathrm{m}^{-2} \mathrm{~K}^{-1}$ and $\lambda_{2}=2 \times 10^{12} \mathrm{~W} \mathrm{~K}^{-1}$ and (b) the Levitus (1982) climatology.

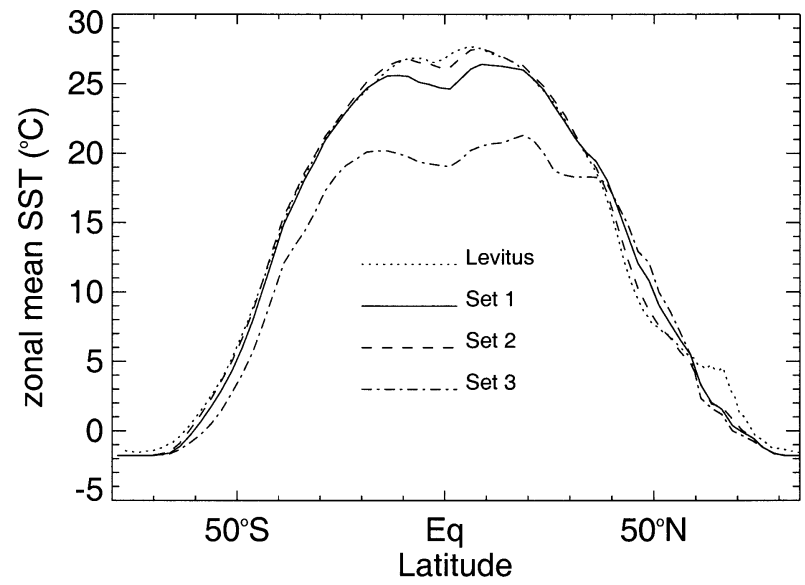

FIG. A2. Zonal-mean sea surface temperatures in the OGCM (version V0.6: "on" mode without surface freshwater flux perturbation; 40-yr means) and calculated from the Levitus (1982) climatology. Three different sets of heat flux parameters $\lambda_{1}$ and $\lambda_{2}$ are used in the model (see text)

large-scale anomalies. It is important that these parameters allow the simulation of sea surface temperatures that are close to observations (Fig. A1).

It is well known that surface heat flux parameterizations have a substantial influence on the stability properties of the THC. In particular, a strong damping of surface temperature anomalies can considerably decrease the stability of the "on"'mode (e.g., Mikolajewicz and Maier-Reimer 1994; Rahmstorf and Willebrand 1995; Lohmann et al. 1996; Prange et al. 1997). Using version V0.6 of our model, we carried out additional experiments to demonstrate the effects of $\lambda_{1}$ and $\lambda_{2}$ on THC stability.

Figure A2 shows zonal-mean sea surface temperatures using three different sets of heat flux parameters. Standard values (see above) are used in set 1 . Set 2

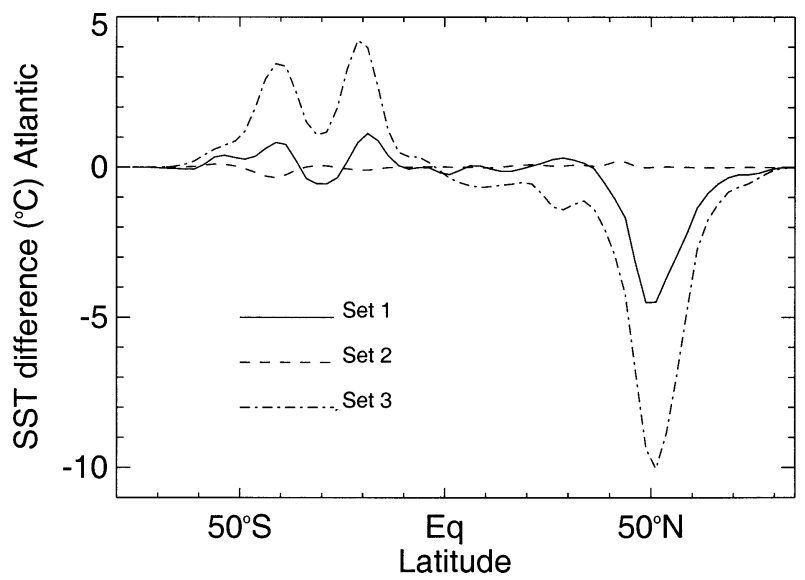

FIG. A3. Differences in zonal mean Atlantic surface temperatures between "on" mode and "off" mode of the THC using three different sets of surface heat flux parameters (see text) to force the OGCM (version V0.6; without surface freshwater flux perturbations; 40-yr means). 


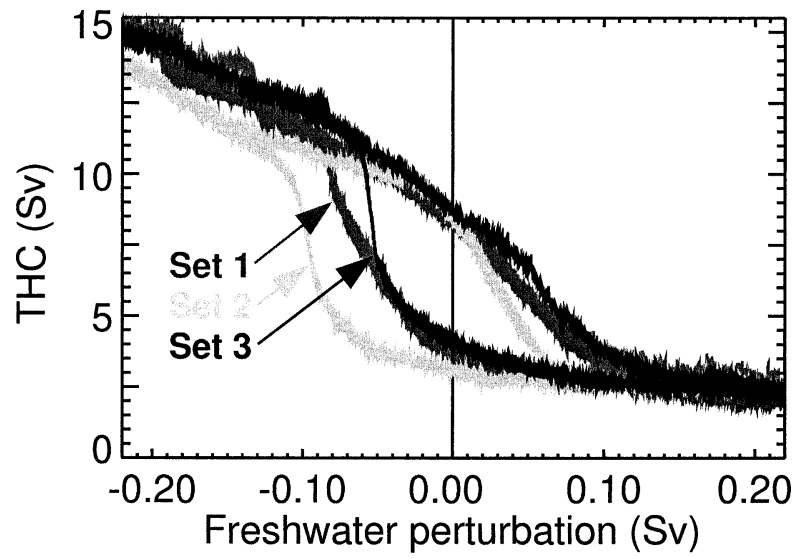

FIG. A4. As in Fig. 6 except that model version V0.6 with three different sets of surface heat flux parameters (see text) is used.

defines a conventional restoring approach, where $\lambda_{2}$ is set to zero and $\lambda_{1}=75 \mathrm{~W} \mathrm{~m}^{-2} \mathrm{~K}^{-1}$. With a thickness of $50 \mathrm{~m}$ for the topmost boxes of the model grid, this corresponds to a restoring timescale of approximately one month. Set 3 consists of values suggested by Rahmstorf and Willebrand (1995); that is, $\lambda_{1}=3 \mathrm{~W}$ $\mathrm{m}^{-2} \mathrm{~K}^{-1}$ and $\lambda_{2}=8 \times 10^{12} \mathrm{~W} \mathrm{~K}^{-1}$. These authors have shown that the thermal boundary condition (1) can be derived from an atmospheric energy balance model with diffusive lateral heat transport. In their derivation, the restoring temperature is strictly defined as the surface temperature that would be reached in the absence of oceanic heat transports. Using actual air temperatures, as we do in our setup, the heat flux parameters of Rahmstorf and Willebrand (1995) are not appropriate, resulting in strongly reduced surface temperatures in low latitudes (Fig. A2).

The model's capability to maintain sea surface temperature anomalies is demonstrated in Fig. A3 for the different sets of heat flux parameters. Applying set 1 or set 3 , we find considerable surface temperature differences between "off" mode and "on" mode in the North Atlantic. The strong restoring of set 2, however, suppresses the development of temperature anomalies. North Atlantic cooling tends to stabilize the "on" mode by increasing the density of North Atlantic water masses. This is clearly expressed in the "stability diagrams", (Fig. A4).

We conclude that our standard set of parameters $\left(\lambda_{1}\right.$ $=15 \mathrm{~W} \mathrm{~m}^{-2} \mathrm{~K}^{-1}, \lambda_{2}=2 \times 10^{12} \mathrm{~W} \mathrm{~K}^{-1}$ ) is a suitable choice, allowing the simulation of observed sea surface temperatures and the maintenance of large-scale temperature anomalies in perturbation experiments.

\section{REFERENCES}

Bryan, F., 1986: High-latitude salinity effects and interhemispheric thermohaline circulation. Nature, 323, 301-304.

, 1987: Parameter sensitivity of primitive equation ocean general circulation models. J. Phys. Oceanogr., 17, 970-986.
Bryan, K., and L. J. Lewis, 1979: A water mass model of the World Ocean. J. Geophys. Res., 84, 2503-2517.

Clark, P. U., S. J. Marshall, G. K. C. Clarke, S. W. Hostetler, J. M. Licciardi, and J. T. Teller, 2001: Freshwater forcing of abrupt climate change during the last glaciation. Science, 293, 283287.

Cummins, P. F., G. Holloway, and A. E. Gargett, 1990: Sensitivity of the GFDL ocean general circulation model to a parameterization of vertical diffusion. J. Phys. Oceanogr., 20, 817-830.

Farrow, D. E., and D. P. Stevens, 1995: A new tracer advection scheme for Bryan and Cox type ocean general circulation models. $J$. Phys. Oceanogr., 25, 1731-1741.

Ganachaud, A., and C. Wunsch, 2000: Improved estimates of global ocean circulation, heat transport and mixing from hydrographic data. Nature, 408, 453-457.

Ganopolski, A., and S. Rahmstorf, 2001: Rapid changes of glacial climate simulated in a coupled climate model. Nature, 409, 153158.

—, V. Petoukhov, S. Rahmstorf, V. Brovkin, M. Claussen, A. Eliseev, and C. Kubatzki, 2001: CLIMBER-2: A climate system model of intermediate complexity. Part II: Model sensitivity. Climate Dyn., 17, 735-751.

Gerdes, R., C. Köberle, and J. Willebrand, 1991: The influence of numerical advection schemes on the results of ocean general circulation models. Climate Dyn., 5, 211-226.

Hall, M. M., and H. L. Bryden, 1982: Direct estimates and mechanisms of ocean heat transport. Deep-Sea Res., 29, 339-359.

Keigwin, L. D., and S. J. Lehman, 1994: Deep circulation change linked to Heinrich Event 1 and Younger Dryas in a mid-depth North Atlantic core. Paleoceanography, 9, 185-194.

Klinger, B. A., and J. Marotzke, 1999: Behavior of double hemisphere thermohaline flows in a single basin. J. Phys. Oceanogr., 29, 382-399.

Leonard, B. P., 1979: A stable and accurate convective modelling procedure based on quadratic upstream interpolation. Comput. Methods Appl. Mech. Eng., 19, 59-98.

Levitus, S., 1982: Climatological Atlas of the World Ocean. NOAA Prof. Paper 13, 173 pp. and 17 microfiche.

Lohmann, G., R. Gerdes, and D. Chen, 1996: Stability of the thermohaline circulation in a simple coupled model. Tellus, 48A, 465-476.

Maier-Reimer, E., and U. Mikolajewicz, 1989: Experiments with an OGCM on the cause of the Younger Dryas. MPI Rep. 39, Hamburg, Germany, 13 pp.

_ _ - and K. Hasselmann, 1993: Mean circulation of the Hamburg LSG OGCM and its sensitivity to the thermohaline surface forcing. J. Phys. Oceanogr., 23, 731-757.

Manabe, S., and R. J. Stouffer, 1988: Two stable equilibria of a coupled ocean-atmosphere model. J. Climate, 1, 841-866.

_ and - 1999: Are two modes of thermohaline circulation stable? Tellus, 51A, 400-411.

Marotzke, J., 1997: Boundary mixing and the dynamics of threedimensional thermohaline circulations. J. Phys. Oceanogr., 27, $1713-1728$.

— mohaline circulation. J. Phys. Oceanogr., 21, 1372-1385.

Mesinger, F., and A. Arakawa, 1976: Numerical methods used in atmospheric models, volume I. GARP Publications Series 17, WMO, 64 pp.

Mikolajewicz, U., and E. Maier-Reimer, 1994: Mixed boundary conditions in ocean general circulation models and their influence on the stability of the model's conveyor belt. J. Geophys. Res., 99, 22 633-22 644.

Molenkamp, C. R., 1968: Accuracy of finite-difference methods applied to the advection equation. J. Appl. Meteor., 7, 160-167.

Munk, W. H., 1966: Abyssal recipes. Deep-Sea Res., 13, 707-730.

— , and C. Wunsch, 1998: Abyssal recipes II: Energetics of tidal and wind mixing. Deep-Sea Res., 45, 1977-2010.

Prange, M., G. Lohmann, and R. Gerdes, 1997: Sensitivity of the thermohaline circulation for different climates-Investigations 
with a simple atmosphere-ocean model. Palaeoclimates, 2, 7199.

Rahmstorf, S., 1995: Bifurcations of the Atlantic thermohaline circulation in response to changes in the hydrological cycle. Nature, 378, 145-149.

— , and J. Willebrand, 1995: The role of temperature feedback in stabilizing the thermohaline circulation. J. Phys. Oceanogr., 25, 787-805.

Roeckner, E., and Coauthors, 1992: Simulation of the present-day climate with the ECHAM model: Impact of model physics and resolution. MPI Rep. 93, Hamburg, Germany, $171 \mathrm{pp}$.

Schäfer-Neth, C., and A. Paul, 2001: Circulation of the glacial Atlantic: A synthesis of global and regional modeling. The Northern North Atlantic: A Changing Environment, P. Schäfer et al., Eds., Springer, 441-462.

Schmittner, A., and T. F. Stocker, 2001: A seasonally forced oceanatmosphere model for paleoclimate studies. J. Climate, 14, $1055-1068$.

— , and A. J. Weaver, 2001: Dependence of multiple climate states on ocean mixing parameters. Geophys. Res. Lett., 28, 10271030 .

Scott, J. R., and J. Marotzke, 2002: The location of diapycnal mixing and the meridional overturning circulation. J. Phys. Oceanogr., 32, 3578-3595.
Stocker, T. F., and D. G. Wright, 1991: Rapid transitions of the ocean's deep circulation induced by changes in surface water fluxes. Nature, 351, 729-732.

-, - and L. A. Mysak, 1992: A zonally averaged, coupled ocean-atmosphere model for paleoclimate studies. J. Climate, 5, 773-797.

Toggweiler, J. R., and B. Samuels, 1995: Effect of Drake Passage on the global thermohaline circulation. Deep-Sea Res., 42, 477500 .

Weber, S. L., 1998: Parameter sensitivity of a coupled atmosphereocean model. Climate Dyn., 14, 201-212.

Willebrand, J., 1993: Forcing the ocean by heat and freshwater fluxes. Energy and Water Cycles in the Climate System, E. Raschke and D. Jacob, Eds., Springer, 215-233.

Winton, M., 1996: The role of horizontal boundaries in parameter sensitivity and decadal-scale variability of coarse-resolution ocean general circulation models. J. Phys. Oceanogr., 26, 289304.

Wright, D. G., and T. F. Stocker, 1992: Sensitivities of a zonally averaged global ocean circulation model. J. Geophys. Res., 97, $12707-12730$

Zhang, J., R. W. Schmitt, and R. X. Huang, 1999: The relative influence of diapycnal mixing and hydrologic forcing on the stability of the thermohaline circulation. J. Phys. Oceanogr., 29, 1096-1108. 